\title{
Analytical Breakdown Voltage Model for Partial SOI- LDMOS Transistor with Buried Oxide Step Structure
}

Jagamohan Sahoo

NIT Durgapur

Rajat Mahapatra ( $\nabla$ rajat.mahapatra@ece.nitdgp.ac.in )

National Institute of Technology Durgapur

\section{Research Article}

Keywords: Analytical model, Partial SOI-LDMOS, Surface electric field, Electric field modulation

Posted Date: April 14th, 2021

DOI: https://doi.org/10.21203/rs.3.rs-335520/v1

License: (c) (i) This work is licensed under a Creative Commons Attribution 4.0 International License. Read Full License 


\section{Abstract}

We have developed a simple physics-based two-dimensional analytical Off-state breakdown voltage model of a PBOSS Silicon-On-Insulator Lateral Diffused Metal Oxide Semiconductor (SOI-LDMOS) transistor. The analytical model includes the expressions of surface potential and electric field distributions in the drift region by solving the 2D Poisson's equation. The electric field at the $\mathrm{Si}-\mathrm{SiO} 2$ surface is modified by creating additional electric field peaks due to the presence of the PBOSS structure. The uniformly distributed electric field results in improving the breakdown voltage. Further, the breakdown voltage is analytically obtained via critical electric field concept to quantify the breakdown characteristic. The model exploits the impact of the critical device design parameters such as thickness and length of the PBOSS structure, doping, and thickness of the drift region on the surface electric field and the breakdown voltage. The proposed model is verified by the results obtained from ATLAS two dimensional simulations. The analytical model is of the high potential from a physical and mathematical point of view to design high voltage SOI-LDMOS transistors for power switching applications.

\section{Full Text}

This preprint is available for download as a PDF.

\section{Figures}

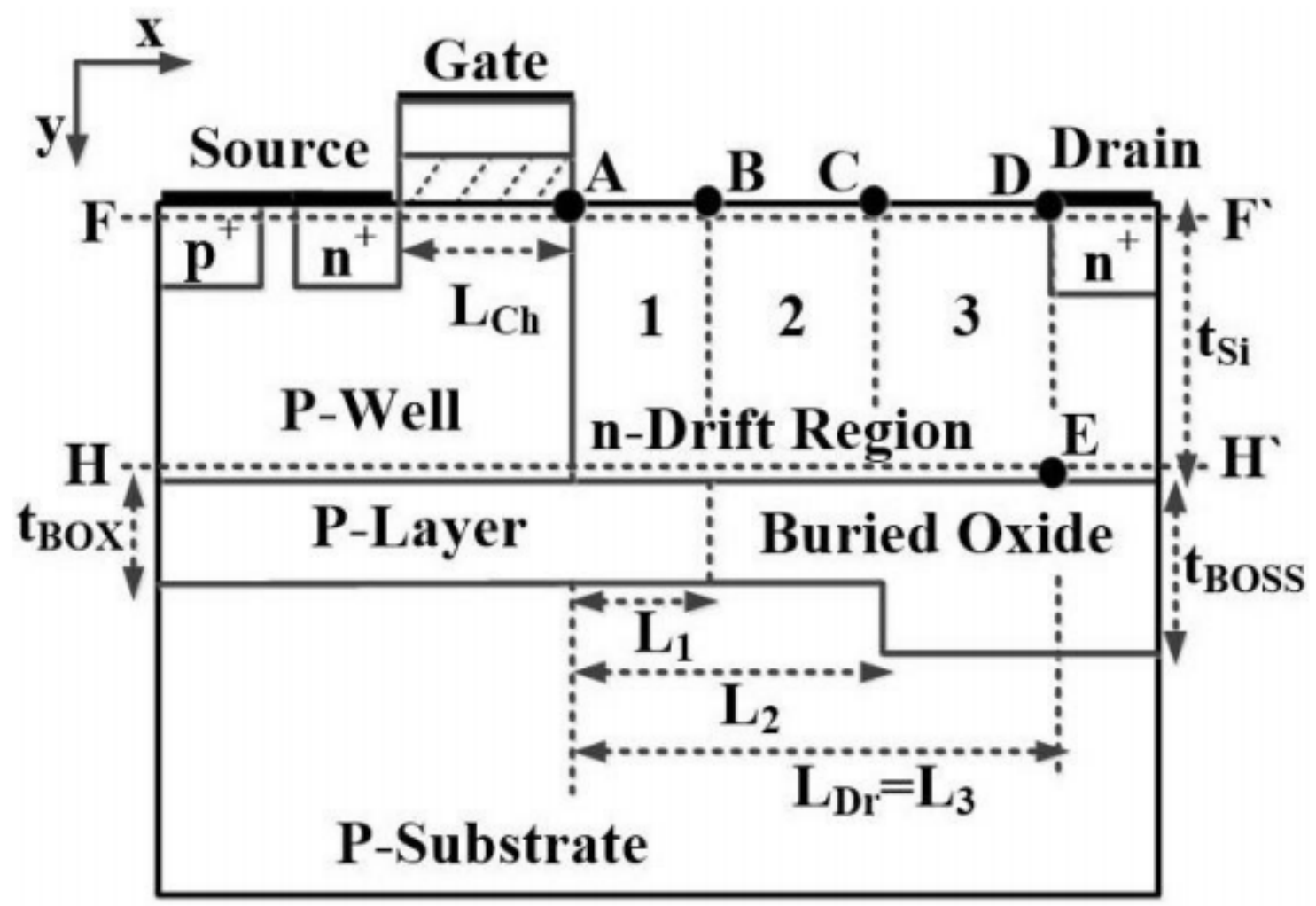

Figure 1 


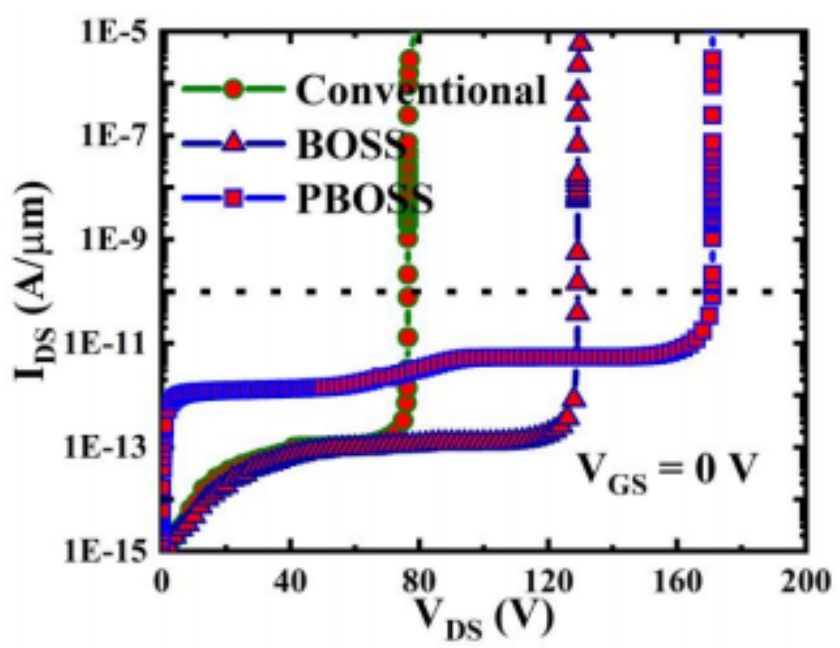

Figure 2

Simulated OFF-state breakdown characteristics of the for the Conventional, BOSS and PBOSS SOILDMOS transistors.
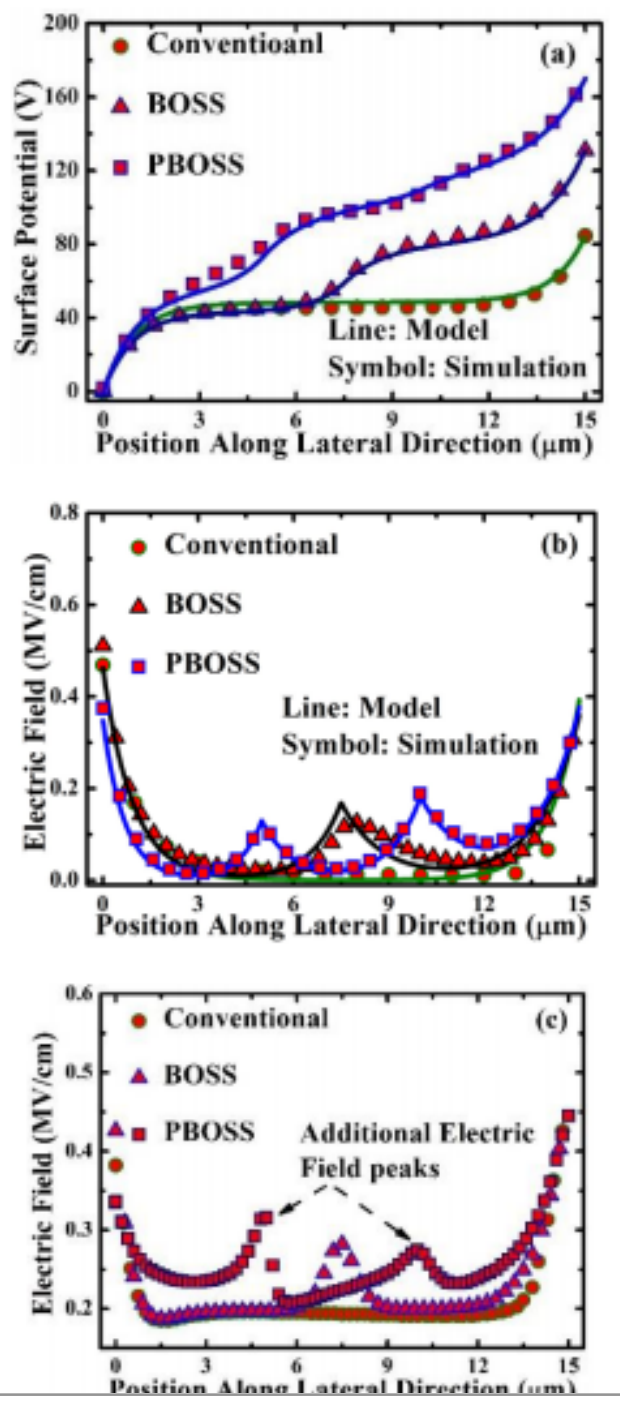

Loading [MathJax]/jax/output/CommonHTML/jax.js 


\section{Figure 3}

Variation of the (a) potential at cross-section $\mathrm{FF}($ b) laterale $\leq$ ctricfieldatcross - sectionFF (c) lateral electric field at cross-section HH' for the Conventional, BOSS and PBOSS SOI-LDMOS transistors. Here VGS $=0$ V, VDS equals to breakdown voltages of each structure. Solid Line - Model, Symbol - Simulation.
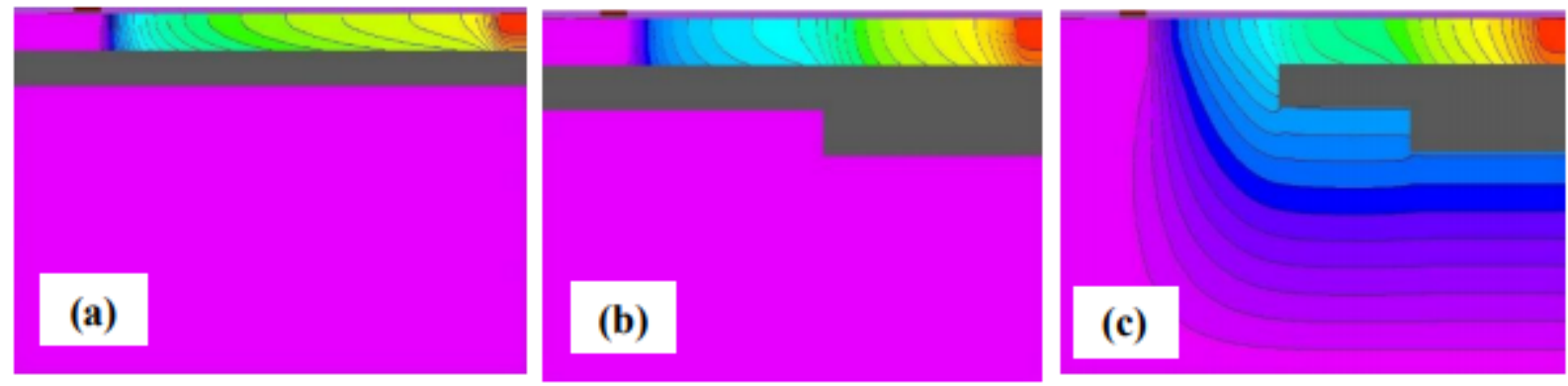

Figure 4

Equipotential contours are shown for the (a) Conventional (b) BOSS (c) PBOSS SOI-LDMOS transistors. Here VGS $=0$ V, VDS equals to breakdown voltages of each structure.
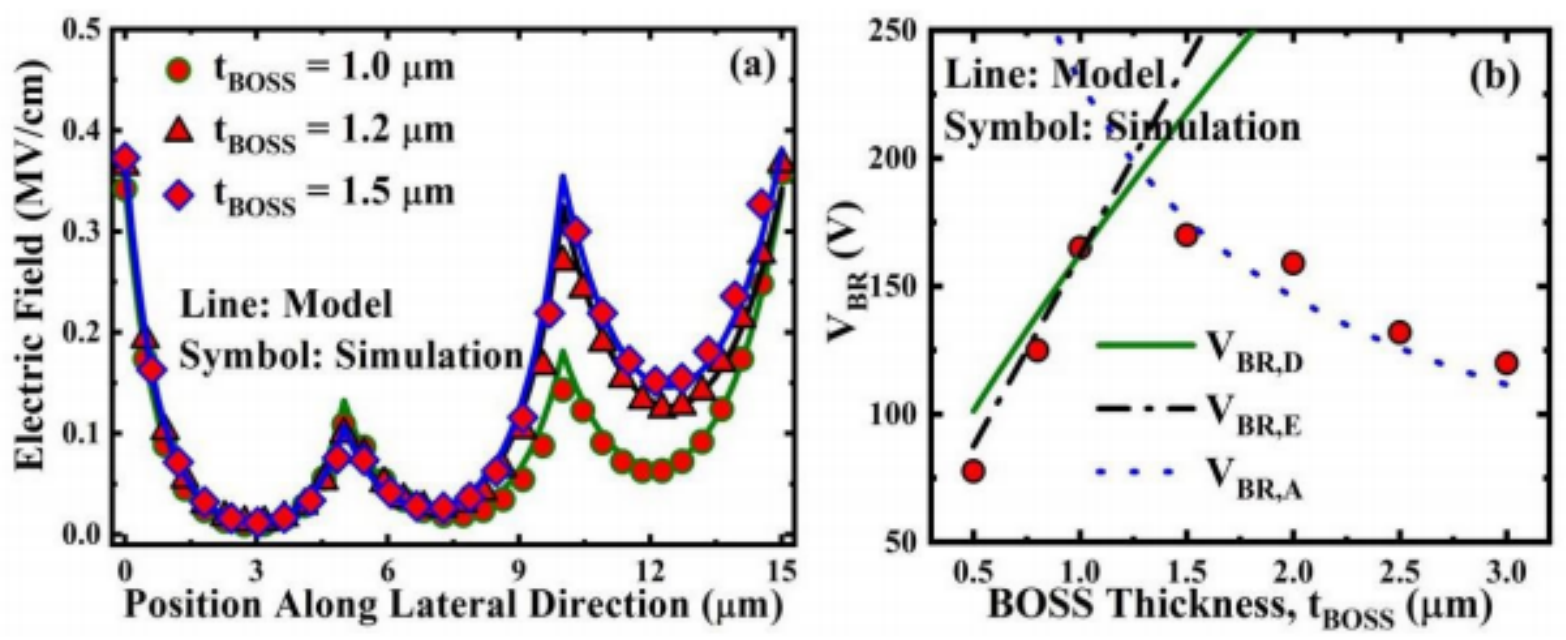

Figure 5

Variation of the (a) lateral electric field at cross-section FF' for different tBOSS (b) VBR with tBOSS for the PBOSS SOI-LDMOS transistor. Solid Line - Model, Symbol - Simulation. 

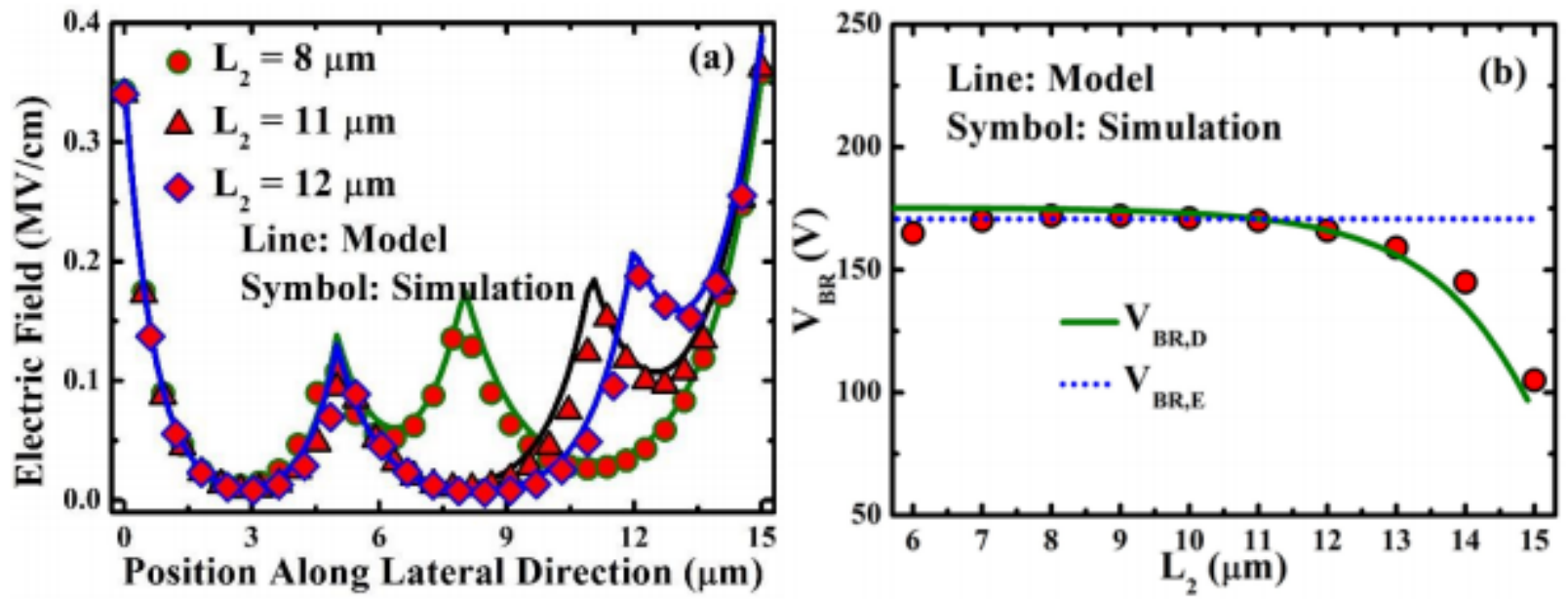

Figure 6

Variation of the (a) lateral electric field at cross-section FF' for different L2 (b) VBR with L2 for the PBOSS SOI-LDMOS transistor. Solid Line - Model, Symbol - Simulation.
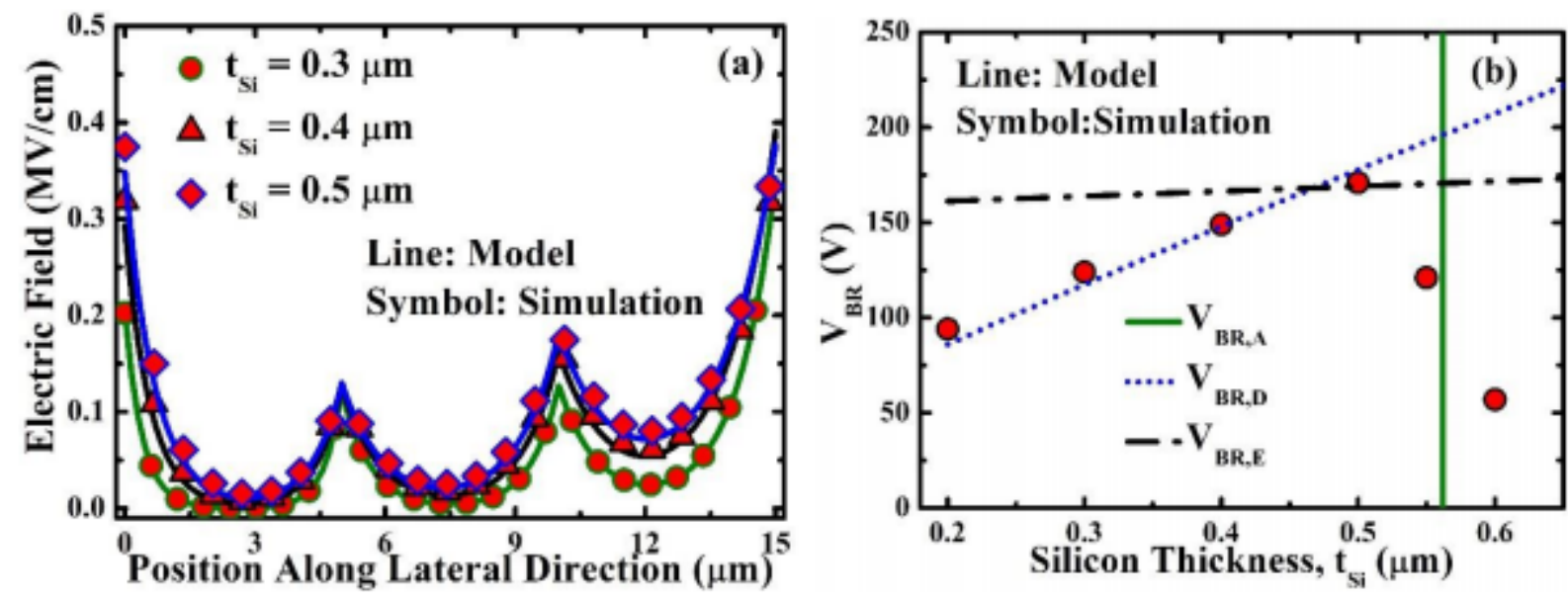

Figure 7

Variation of (a) the lateral electric field at cross-section FF' for different tSi (b) VBR with tSi for the PBOSS SOI-LDMOS devices. Solid Line - Model, Symbol - Simulation. 

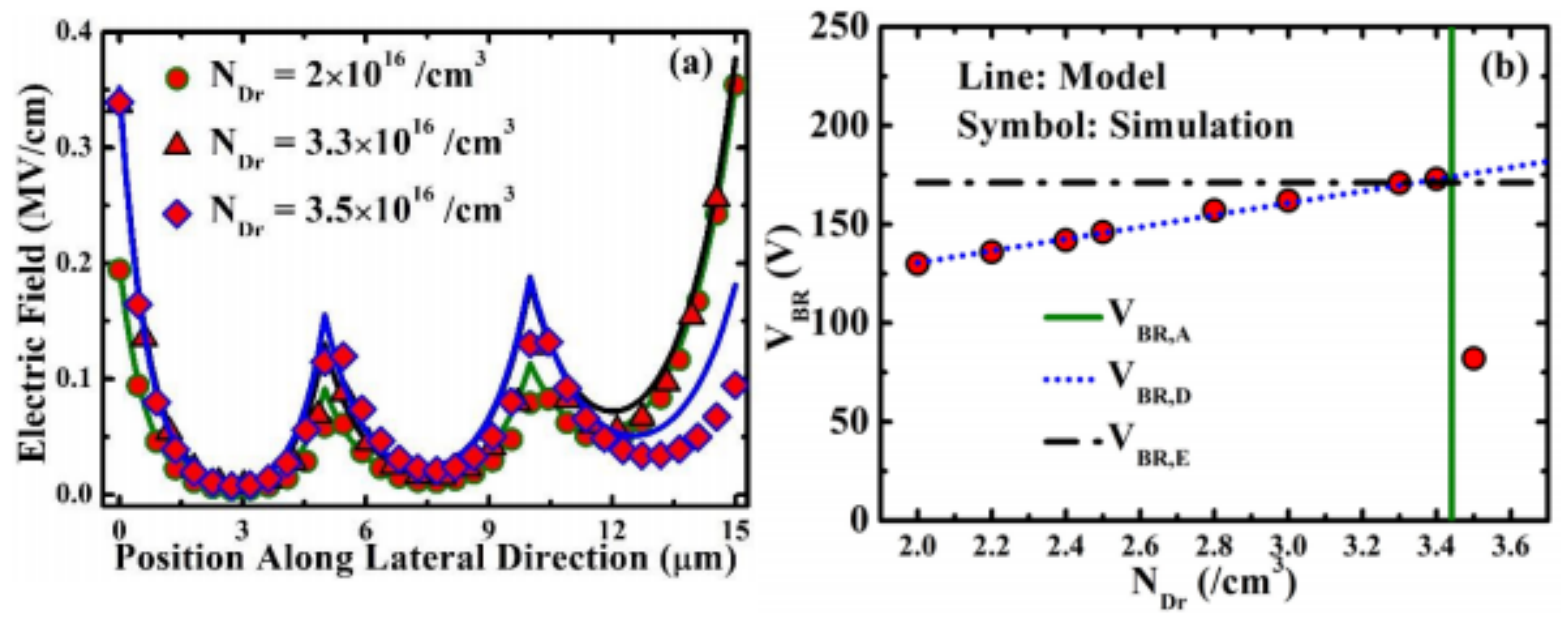

Figure 8

Variation of the (a) lateral electric field at cross-section FF' for different NDr (b) VBR with NDr for the PBOSS SOI-LDMOS devices. Solid Line - Model, Symbol - Simulation. 